\title{
Thermophysical Properties of Lysozyme (Protein) Solutions
}

\author{
Jiaching Liu* and Wen-Jei Yang† \\ University of Michigan, Ann Arbor, Michigan 48109
}

\begin{abstract}
Thermophysical properties of protein solutions are determined. The solutions are composed of the lysozyme crystals with a $0.1 \mathrm{M}$ sodium acetate and $5 \% \mathrm{NaCl}$ solution as the buffer $(\mathrm{pH}=4.0)$. Though lysozyme is a well known protein, the thermophysical properties of its solutions are still unknown. The properties being measured include specific heat, thermal conductivity, dynamic viscosity, and surface tension. The protein concentrations are varied. Thermal diffusivity is calculated using the measured results. The purpose of the research is to measure thermophysical properties of lysozyme solutions and serve as the data bank for controlling and modeling the crystal growth process on earth as well as in space.
\end{abstract}

\section{Nomenclature}

$C_{p}=$ specific heat

$d_{e}=$ diameter of equator of the pendant drop

$d_{s}=$ diameter of selected plane of the pendant drop

$g=$ gravity

$H=$ function of $S$; a tabulated value

$k$. thermal conductivity

$m=$ mass of the sample

$Q=$ heat flow per unit time

$\tilde{S}=d_{s} / d_{e}$

$T=$ temperature

$T_{a}=$ temperature of the guard heater

$T_{b}=$ temperature of the bottom surface of the test cell

$T_{c}=$ temperature of the upper surface of the test cell

$t=$ effux time for macromolecules or time in calculating specific heat

$t_{0}=$ effux time for water

$V=$ voltage drop across heating plate

$\Delta \rho=$ density difference between solution and air

$\mu=$ viscosity of solution

$\mu_{0}=$ viscosity of solvent

$\rho=$ density of solution

$\rho_{0}=$ density of solvent

$\sigma=$ surface tension

\section{Introduction}

$\mathbf{T}$ HE determination of protein structure has always been a vital and crucial step toward the understanding of biological functions. Numerous methods have been developed for this purpose and, when coupled with the use of a super computer, can reduce the work time from 2.5 yr to 1-2 weeks. ${ }^{1}$ However, one main problem still remains in the determination of protein structure: the requirement of a single crystal. The growth of high-quality three-dimensional crystals still remains an art rather than a science, because some crystals can be grown easily, or take months to grow, and some cannot be obtained in the crystalline form at all. ${ }^{2}$ Lysozyme has been served as a model system to study the crystallization process because of its readiness to crystallize from a solution. Despite of the intensive study in the crystallization process of lysozyme and the attempts to model its crystal growth, none of the available literature dealt with the thermophysical properties which are vital in evaluating the validity of a model. The methods used in this investigation can also be used to measure

Received March 5, 1991; revision received June 1, 1991; accepted for publication June 7, 1991. Copyright (C) 1991 by the American Institute of Aeronautics and Astronautics, Inc. All rights reserved.

*Visiting Scholar, Assistant Scientist, Chung-Shan Institute of Technology, P. O. Box 9008-9-2 Lung-Tan, Taiwan, R.O.C.

†Professor, Department of Mechanical Engineering and Applied Mechanics. Associate Fellow AIAA. the thermophysical properties of other proteins and can be the first step toward a successful crystal growth.

Macromolecules, such as lysozyme, which has a molecular weight of 14,000 and a polypeptide chain of 129 amino acids, can be considered as rigid rods which possess internal bonding which allows little or no latitude in the location of one part of the molecule relative to another. It is likely that a certain amount of solvent will often be an inherent part of the macromolecules. Protein molecules, for example, possess ionic groups and polar groups, which in a polar solvent, will generally be associated with one or more solvent molecules. This solvation effect is only found in macromolecules, especially in proteins. Another distinguished difference between proteins and other substances is that protein molecules in solution bear electrostatic charges. Even at the isoelectric point, the molecules are multipolar ions; i.e., they contain many positive and negative charges. The transport properties of proteins are therefore undoubtedly influenced by electrostatic forces. A low-molecular-weight electrolyte, such as sodium acetate, is needed to eliminate any such influence.

The presence of macromolecules in particular solvents can give rise to a drastic increase in viscosity. It is much greater than that found for equivalent concentrations of low-molecular-weight materials because of the enormous difference in dimensions between macromolecules and solvent molecules. In general, the increase of viscosity depends upon a number of factors such as the nature of the solvent, the type of polymers, the molecular weight of the macromolecules, the concentration, and the temperature. Since the expansion of a macromolecular coil is a function of solvent, and the viscosity of a macromolecule solution depends upon the volume occupied by macromolecules, ${ }^{3}$ the viscosity data obtained from this research are to interpret the behavior of the lysozyme solution under the specific conditions of measurements.

Thermal conductivity is one of the most important parameters in the analysis of thermal behavior. It plays a major role in the rate of heat removal in protein crystallization which is an exothermic reaction. It is also the basic property to calculate some important parameters in heat transfer such as Prandtl and Nusselt numbers. One difficulty in measuring the thermal conductivity for liquids is that the temperature gradient must not cause the initiation of convection. The heat flow direction in this investigation is intended to be parallel to that of gravity in order to eliminate the possibility of natural convection caused by thermal instability. In contrast to the use of a large, expensive adiabatic calorimeter for the measurement of specific heat, differential scanning calorimetry (DSC) was employed in this study. Although DSC is less accurate than a good adiabatic calorimeter, its accuracy is adequate for most uses, and its advantage of speed and low cost makes it the outstanding instrument of choice for most modern calorimetry. ${ }^{4}$ 
A great many procedures have been developed for the determination of interfacial tension, of which the majority are just barely workable, characterized by low precision, and lack of versatility. ${ }^{5}$ The methods depend upon the rise of liquid level in a capillary tube, the force required to pull a wire ring out of a liquid surface, the weight or volume of drops falling from a vertical tube of known size, the maximum pressure required to form bubbles in a liquid from a tube of known size, and the geometric characteristic factor of drops or bubbles. The pendant drop method is a widely used one, requires only small quantities of liquid, and is applicable to experimentally difficult situations. Once the surface is formed, it is not subjected to any changes due to outside influence prior to or during the measurement. The method also permits an accurate study of the changes in surface composition with time in dilute solutions, a phenomenon of predominant importance in study of various colloidal systems.

\section{Experimental Apparatus and Procedure}

\section{Viscosity}

Two main pieces of apparatus generally used for solution viscosity measurements are the Ostwald viscometer and a modified version called the Ubbelohde viscometer. The necessity of using an identical volume of liquid for each measurement during an experiment in the Ostwald viscometer clearly leads to a potential source of error. This problem is overcome in the Ubbelohde viscometer by having a third arm open to the atmosphere. Since the same marks are always used to monitor the liquid through measuring bulb, the pressure head and the volume of liquid flow through the capillary will always be the same, as shown in Fig. 1. The latter will be used to determine the viscosities of the lysozyme solutions as a function of concentrations at room temperature. Measurements of viscosity are usually made by comparing effux time $t$ required for a specific volume of macromolecular solution to flow through a capillary tube with corresponding effux time $t_{0}$ of the solvent, which, in this experiment, is water. Starting from the Hagen-Poiseuille equation, ${ }^{6}$ the effux time $t, t_{0}$ can be related to the viscosity of the solvent by the following equation:

$$
\mu=\mu_{0}\left(t \rho / t_{0} \rho_{0}\right)
$$

The experimental procedure is as follows:

1) Rinse the viscometer with solvent (water) and let it drain.

Put the viscometer in a constant temperature bath $\left(27^{\circ} \mathrm{C}\right)$.

2) Transfer $10.0 \mathrm{ml}$ of the filtered solvent (water) to the viscometer.

3) After temperature reached equilibrium, apply pressure to bring the liquid up to desired level in the measuring bulb.

4) Open all tubes to atmosphere and allow the liquid to drain down the capillary. Start the timer exactly as the meniscus passes the upper graduation mark and stop it exactly as the meniscus passes the lower mark.

5) Determine the effux time three times. If the readings agree within $0.1 \mathrm{~s}$ or $0.1 \%$ of their mean, whichever is larger, then the reading will be used in the calculation of viscosity. If not, repeat step 4.

6) Add $10 \mathrm{ml}$ of lysozyme $(50 \mathrm{mg} / \mathrm{ml})$ solution to the viscometer and mix the solution well by applying nitrogen pressure.

7) Repeat steps 3 and 4. Add another aliquot of solvent as in step 5 to obtain the desired concentrations.

8) Use Eq. (1) to calculate the viscosities.

\section{Thermal Conductivity}

The apparatus built for this purpose is schematically shown in Fig. 2. The apparatus is a simplified version of ASTM C201. The silicon carbide plate was substituted by an aluminium plate to provide uniform heating. Several experiments were

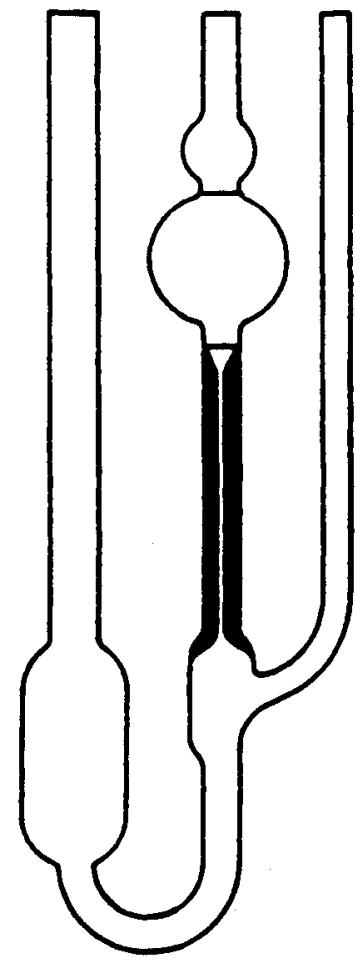

Fig. 1 Ubbelohde viscometer.

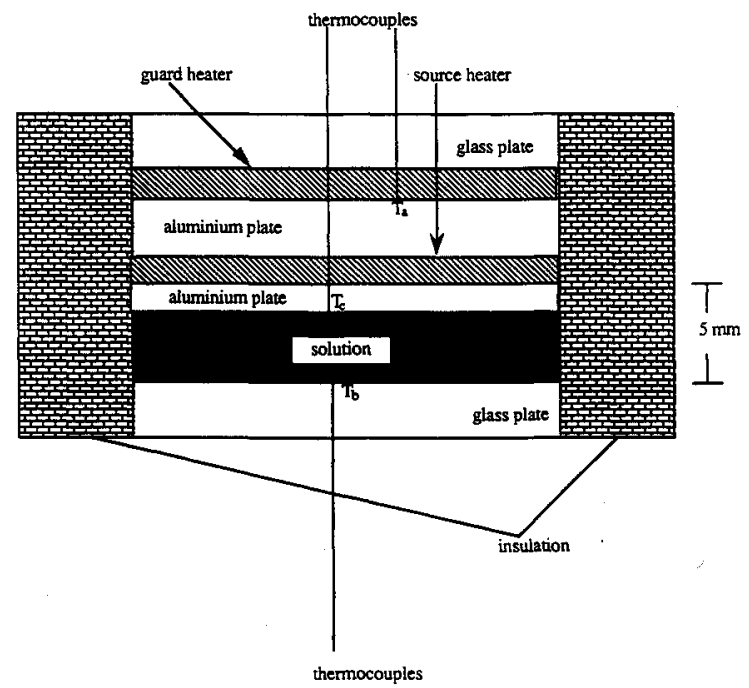

Fig. 2 Apparatus for thermal conductivity measurement.

conducted to determine the required thickness for insulation. Two $275 \Omega$ thermofoils from Minco Co. were used as a source heater and a guard heater to generate steady heat flow across the test element. The heat flow direction is intended to be parallel to that of gravity in order to eliminate the possibility of natural convection caused by thermal instability. The thickness of the test cell is $5 \mathrm{~mm}$. The temperature difference across the liquid layer $\left(T_{c}\right.$ and $\left.T_{b}\right)$ and of the guard heater $\left(T_{a}\right)$ were monitored using a Copper-Constantan thermocouple. The output temperature profiles were recorded by an Omega DAR 130 multichannel temperature recorder.

After several experiments were conducted to determine the required thickness, a RTV silicon foam, with a thickness of $2 \mathrm{~cm}$, was applied on the top and the perimeter of the apparatus to ensure one-dimensional heat transfer. The guard heater was able to supply enough energy to force the energy produced by the source heater to be conducted through the test cell instead of conducting away from it. The temperature difference gradient can be obtained by dividing the temper- 
ature difference (at steady state) across the test cell by the spacing of the test cell. Once this information is known, the thermal conductivity can be evaluated by Fourier's conduction law.

The experimental procedure is as follows:

1) Turn on the temperature recorder.

2) Carefully fill the test cell with the lysozyme solution to eliminate any air bubbles in the cell.

3) Turn on the source heater and adjust the transformer to the desired voltage.

4) Turn on the guard heater and adjust the voltage across the guard heater so that $T_{a}$ and $T_{b}$ remain the same.

5) Observe if the system has reached a steady state with the current readings of the voltage drops. If not, adjust the voltage drop for the guard heater again.

6) Record the voltage drops and the temperature difference across the test cell.

7) Use Fourier's conduction law to calculate the conductivity for the solution.

\section{Specific Heat}

In DSC an average-temperature circuit measures and controls the temperature of sample and reference holders to conform to a predetermined time-temperature program. When the sample undergoes a thermal transition, the power to the two heaters is adjusted to maintain their temperature, and a signal proportional to the power difference is plotted on the recorder. The area under the resulting curve is a direct measure of the heat of transition. The DSC used in measuring the specific heat in this investigation was a DSC-7 by PerkinElmer Co. Gray ${ }^{7}$ proposed a method to measure $C_{p}$ with a DSC, but it is too time consuming. Since a DSC is able to generate data of heat flow versus the temperature easily, an alternative way of measuring $C_{p}$ was used in this study. The net heat flow (total minus base line) has the unit of joule/min and can be expressed as

$$
\frac{\mathrm{d} Q}{\mathrm{~d} t}=\frac{\mathrm{d} Q}{\mathrm{~d} T} \frac{\mathrm{d} T}{\mathrm{~d} t}
$$

where $\mathrm{d} T / \mathrm{d} t$ is the temperature rise.

At a constant pressure

$$
\frac{1}{m} \frac{\mathrm{dQ}}{\mathrm{d} T}=C_{p}
$$

or

$$
C_{p}=\frac{\mathrm{d} Q / \mathrm{d} t}{\mathrm{~d} T / \mathrm{d} t} \frac{1}{m}
$$

The experimental procedure reads:

1) Weigh the DSC cells individually with caps.

2) Run the experiments with empty cells (with their caps) to obtain a base line.

3) Run the experiments with one cell loaded with the lysozyme solution under the same conditions as in step 2 .

4) Subtract the base line from the data obtained in step 3.

5) Calculate $C_{p}$ using Eq. (2).

\section{Surface Tension}

The method consists of suspending a small drop of liquid to be tested from the end of a vertical tube mounted in a thermostat. The size of a pendant drop is most conveniently gauged by measuring its diameter at the equator, and the shape can be described by giving the diameter measured at two different horizontal planes. One diameter is at the plane of the equator, and the other is taken at a distance from the end of the equatorial diameter (Fig. 3); the shape can be described by the ratio

$$
S=\left(d_{s} / d_{e}\right)
$$

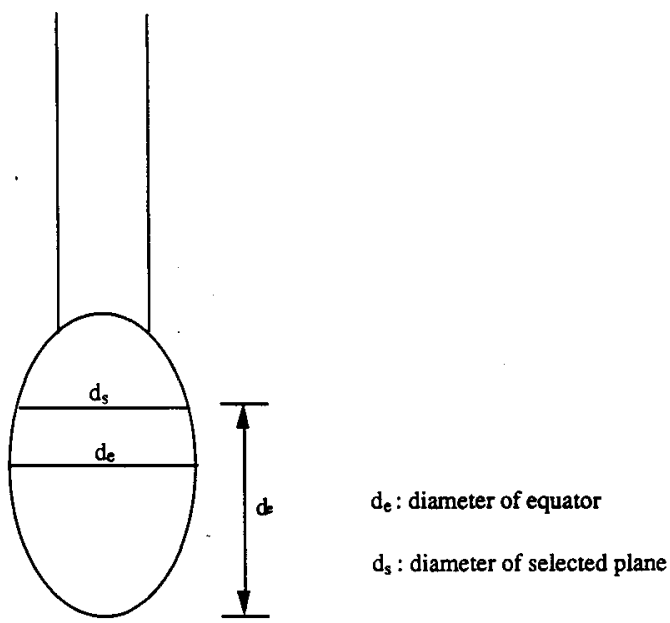

Fig. 3 Geometric constant of a pendant drop.

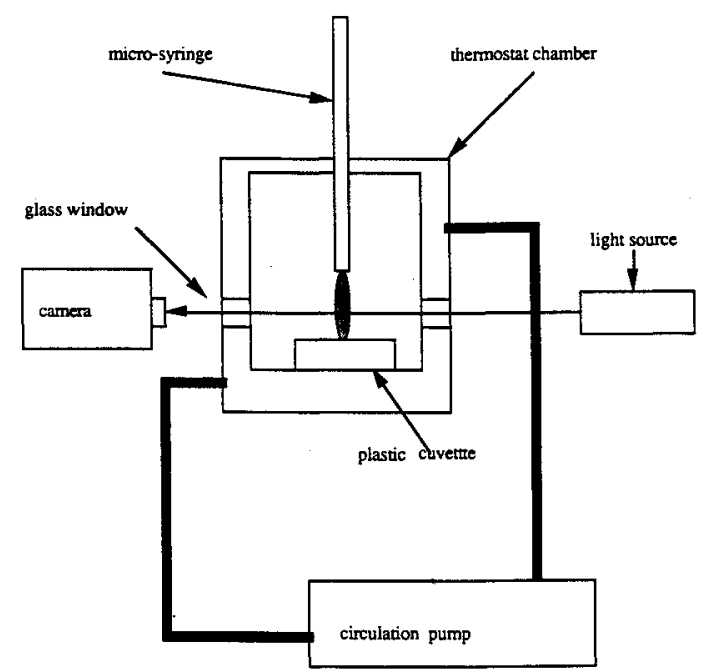

Fig. 4 Apparatus for surface tension measurement.

where, $d_{e}$ is the diameter at the equator and $d_{s}$ denotes the diameter of the plane at a distance $d_{e}$ up from the equator.

The surface tension of the pendant drop can be determined from the equation

$$
\sigma=\left(g \Delta \rho d_{e}^{2} / H\right)
$$

where, $\sigma$ represents the surface tension (or interfacial tension); $g$, gravity; $\Delta \rho$, density difference; and $H$, geometry characteristic factor, which is a function of $S$. The functional relationship between $H$ and $S$ has been numerically integrated by Andreas et al. ${ }^{8}$ and expanded by Adamson. ${ }^{5}$

The apparatus used in measuring the surface tension in this study consists of a light source, a thermostat chamber, a drop forming tip, and a camera with a close-up lens as shown in Fig. 4. The drop hangs from a vertical, cylindrical tip in the thermostat. To prevent the loss of liquid by evaporation, the chamber of the thermostat is totally closed and a curvet filled with the solution of the same composition was placed underneath the drop in the thermostat. The drop forming tip for the surface tension measurement was made by welding a short length of 2-mm Pyrex tubing on a standard Hamilton 500- $\mu$ l teflon plunger syringe. The surface of the drop would be a surface of revolution whose shape and size can be recorded by a camera and later analyzed by a Gray $F / X$ image processing system.

The experimental procedure reads:

1) Turn on the circulation pump and light source. 
2) Force $0.02 \mathrm{ml}$ of solution through the drop forming syringe to form a pendant drop.

3) Wait for $5 \mathrm{~min}$ in order for the drop to reach thermal equilibrium.

4) Record the image of the drop with a camera with a closeup lens.

5) Repeat steps $2-4$ seven times.

6) Use the Gray F/X image processing system to enlarge the image and measure $d_{e}$ and $d_{s}$.

7) Compute the ratio $S$ by using Eq. (3) and find out the corresponding $H$ values in Ref. 5 .

8) Calculate the surface tension by using Eq. (4).

\section{Results and Discussion}

\section{Thermal Conductivity and Thermal Diffusivity}

The results of thermal conductivity measurements are shown in Table 1 and Fig. 5. The data of water agree well with the thermal conductivity found in existing literature. The time required for the temperatures to reach a steady state was about 25-30 min. Air bubbles were carefully removed from the liquid to avoid any possible error. As can be seen in Fig. 5 and Table 1, adding $\mathrm{NaCl}$ and sodium acetate to water increases the conductivity of the system. But adding lysozyme crystals to the buffer decreases the thermal conductivity significantly, from $0.718 \mathrm{~W} / \mathrm{m}^{\circ} \mathrm{C}$ for pure buffer to $0.269 \mathrm{~W} / \mathrm{m}^{\circ} \mathrm{C}$ for $10 \mathrm{mg} / \mathrm{ml}$ at $30^{\circ} \mathrm{C}$. As the concentration of lysozyme was raised beyond $10 \mathrm{mg} / \mathrm{ml}$ the conductivity started to increase and finally reached $0.786 \mathrm{~W} / \mathrm{m}^{\circ} \mathrm{C}$ at $40 \mathrm{mg} / \mathrm{ml}$. The trend remained the same when the temperature was $40^{\circ} \mathrm{C}$, but was less obvious than at room temperature. At $50^{\circ} \mathrm{C}$, the conductivity first increases when lysozyme was added to the sys-

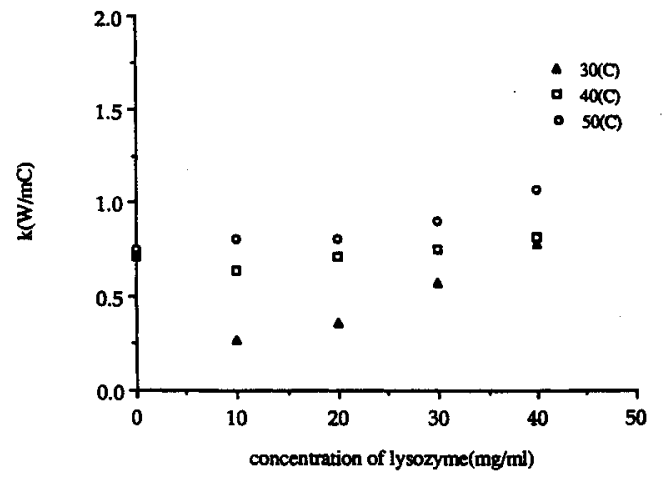

Fig. 5 Thermal conductivities of lysozyme solutions.

Table 1 Results of thermal conductivity measurements, $\mathrm{W} / \mathrm{m}^{\circ} \mathrm{C}$

\begin{tabular}{lcccccc}
\hline & Water & Buffer & $10 \mathrm{mg} / \mathrm{ml}$ & $20 \mathrm{mg} / \mathrm{ml}$ & $30 \mathrm{mg} / \mathrm{ml}$ & $40 \mathrm{mg} / \mathrm{ml}$ \\
\hline $30^{\circ} \mathrm{C}$ & 0.619 & 0.718 & 0.269 & 0.369 & 0.577 & 0.786 \\
$40^{\circ} \mathrm{C}$ & 0.632 & 0.730 & 0.638 & 0.719 & 0.725 & 0.821 \\
$50^{\circ} \mathrm{C}$ & 0.632 & 0.745 & 0.770 & 0.839 & 0.856 & 1.02 \\
\hline \hline
\end{tabular}

tem, then reached a plateau when the concentration was about $10-20 \mathrm{mg} / \mathrm{ml}$ and increased again when the concentration was greater than $20 \mathrm{mg} / \mathrm{ml}$. The thermal conductivity of a lysozyme solution increases with temperature as a given concentration. However, the increase is more significant at the lower concentrations $(0-20 \mathrm{mg} / \mathrm{ml})$ than at the higher ones $(20-40 \mathrm{mg} /$ $\mathrm{ml})$. The error in the measuring of heat flow is about $1 \%$ and the accuracy of the temperature recorder is $1.5^{\circ} \mathrm{C}$. The combination of these two terms results in an uncertainty of about $6 \%$.

The results of the calculations of thermal diffusivity are shown in Table 2 and Fig. 6 . Since the specific heat and density are constants in the range of investigation, the overall trends of thermal diffusivity resemble that of thermal conductivity. The decrease of thermal conductivity to below that of pure water is caused by the polyamide nature of proteins, which

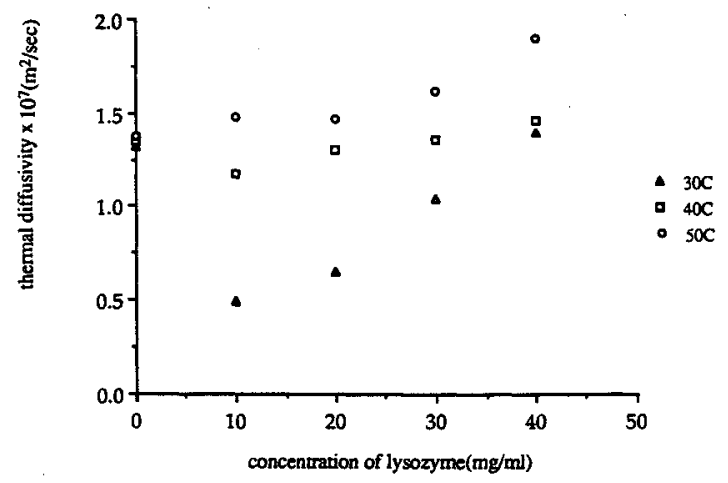

Fig. 6 Thermal diffusivity of lysozyme solutions.

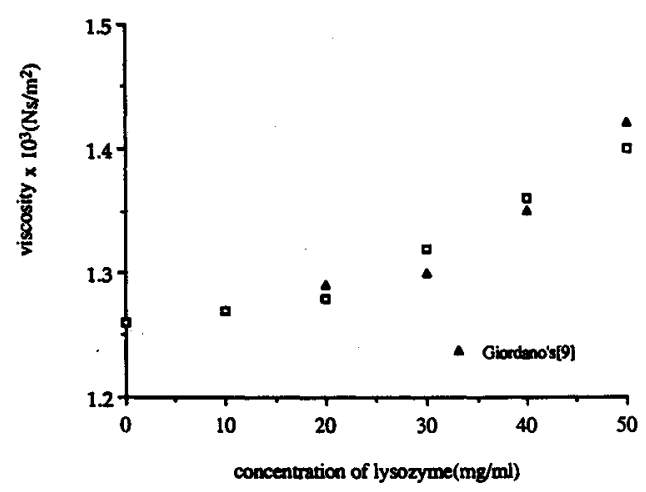

Fig. 7 Viscosities of lysozyme solutions.

Table 2 Results of calculations of thermal diffusivity $\mathrm{m}^{2} / \mathrm{s} \times 10^{7}$

\begin{tabular}{lcccccc}
\hline & Water & Buffer & $10 \mathrm{mg} / \mathrm{ml}$ & $20 \mathrm{mg} / \mathrm{ml}$ & $30 \mathrm{mg} / \mathrm{ml}$ & $40 \mathrm{mg} / \mathrm{ml}$ \\
\hline $30^{\circ} \mathrm{C}$ & 1.47 & 1.32 & 0.492 & 0.65 & 1.04 & 1.4 \\
$40^{\circ} \mathrm{C}$ & 1.50 & 1.35 & 1.17 & 1.30 & 1.36 & 1.46 \\
$50^{\circ} \mathrm{C}$ & 1.5 & 1.38 & 1.48 & 1.47 & 1.62 & 1.9 \\
\hline \hline
\end{tabular}

Table 3 Results of viscosity measurements

\begin{tabular}{lllccccc}
\hline \hline & Water & Buffer & $10 \mathrm{mg} / \mathrm{ml}$ & $20 \mathrm{mg} / \mathrm{ml}$ & $30 \mathrm{mg} / \mathrm{ml}$ & $40 \mathrm{mg} / \mathrm{ml}$ & $50 \mathrm{mg} / \mathrm{ml}$ \\
\hline$\# 1(\mathrm{~s})$ & 144 & 158 & 162 & 161 & 167 & 172 & 177 \\
$\# 2(\mathrm{~s})$ & 144 & 159 & 161 & 163 & 167 & 172 & 177 \\
$\# 3(\mathrm{~s})$ & 143 & 160 & 159 & 161 & 167 & 172 & 177 \\
$\# 4(\mathrm{~s})$ & 143 & 159 & 159 & 161 & 167 & 172 & 176 \\
$\begin{array}{l}\#(\mathrm{~s}) \\
\text { average(s) dy- }\end{array}$ & 143 & 161 & 160 & 162 & 166 & 172 & 176 \\
$\begin{array}{l}\text { namic viscosity } \\
\left(\mathrm{Ns} / \mathrm{m}^{2}\right) \times 10^{3}\end{array}$ & 143.4 & 159.4 & 160.2 & 161.6 & 166.8 & 172.0 & 176.6 \\
$\quad \begin{array}{l}\text { kinematic vis- } \\
\text { cosity }\end{array}$ & 1.14 & 1.26 & 1.27 & 1.28 & 1.32 & 1.36 & 1.4 \\
$\left(\mathrm{~m}^{2} / \mathrm{s}\right) \times 10^{7}$ & 1.14 & 1.18 & 1.18 & 1.18 & 1.21 & 1.23 & 1.26 \\
\hline \hline
\end{tabular}


has a lower thermal conductivity than that of water. The increase of thermal conductivity at high concentrations is conjectured to be caused by the increase of both molecular and momentum diffusivity.

\section{Viscosity}

The viscosity measurements of the lysozyme solutions are presented in Fig. 7 and Table 3. The stopwatch used in the viscosity measurements has a precision of $0.1 \mathrm{~s}$. An uncertainty analysis indicated that the uncertainty for the results of viscosity data is less than $0.07 \%$ by assuming there is no uncertainty in density. There is a large increase in dynamic viscosity when the salts (sodium acetate and sodium chloride) were added to water: Increasing the concentration of lysozyme had a negligible influence on the viscosity of the system until the concentration reached $20 \mathrm{mg} / \mathrm{ml}$, where the viscosity started to increase rapidly. The viscosities measured were larger than those reported by Giordano et al., ${ }^{9}$ who studied the viscosities of lysozyme solutions with concentrations ranging from 0.2 to $26 \%$ by weight of protein in water. The difference in viscosity is believed to be due to the absence of salts in the system. When factoring out the influence of the salts, the results obtained in this section were very close to Giordano's 6 (as shown in Fig. 7). The reason for the abrupt change in slope at about $20 \mathrm{mg} / \mathrm{ml}$ is not the subject of the study, but it might be attributed to the saturation of the lysozyme solution. ${ }^{10}$

\section{Specific Heat}

The DSC study showed that the specific heat is almost independent of the temperature for the buffer used. Other lysozyme solutions at various concentrations show the same tendency. As shown by the DSC study, the specific heat is almost independent of temperature. The specific heat of the buffer is slightly larger than that of water. Adding lysozyme

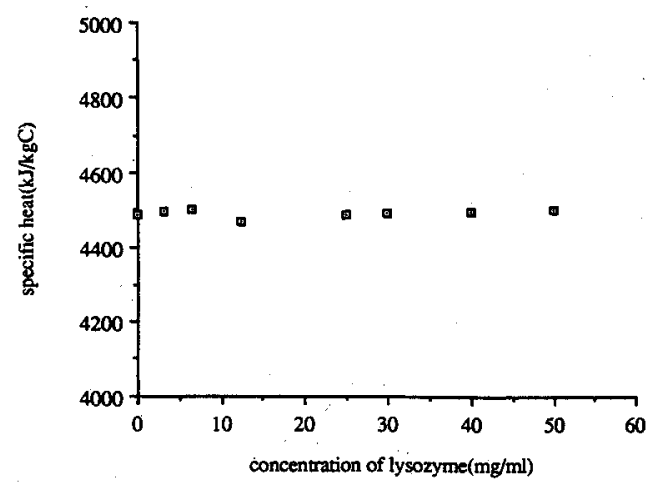

Fig. 8 Specific heat vs concentration for lysozyme solutions. to the buffer shows little change in the specific heat in the range investigated. The final results are plotted in Fig. 8. Since the specific heat is defined as the amount of energy required to raise the temperature of a material of unit mass one degree, it is reasonable for the specific heat of lysozyme solutions to remain practically independent of lysozyme concentration because only a very small percentage of lysozyme $(1-5 \%)$ by weight was added to the system. The uncertainty suggested by the manufacturer in measuring specific heat is less than $2 \%$.

\section{Surface Tension}

All the pendant drop measurements reported in this section were taken $5 \mathrm{~min}$ after the formation of the drop. A 5 -min time period was selected because the surface tension of liquids

a)

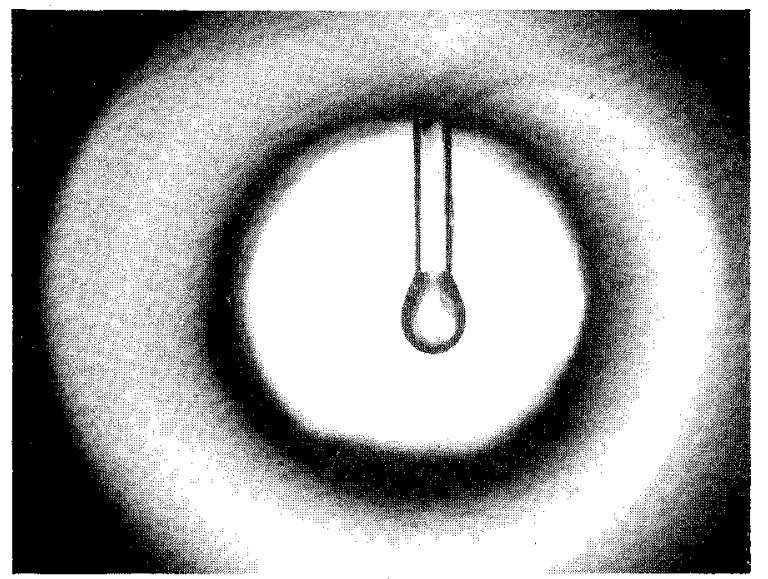

b)

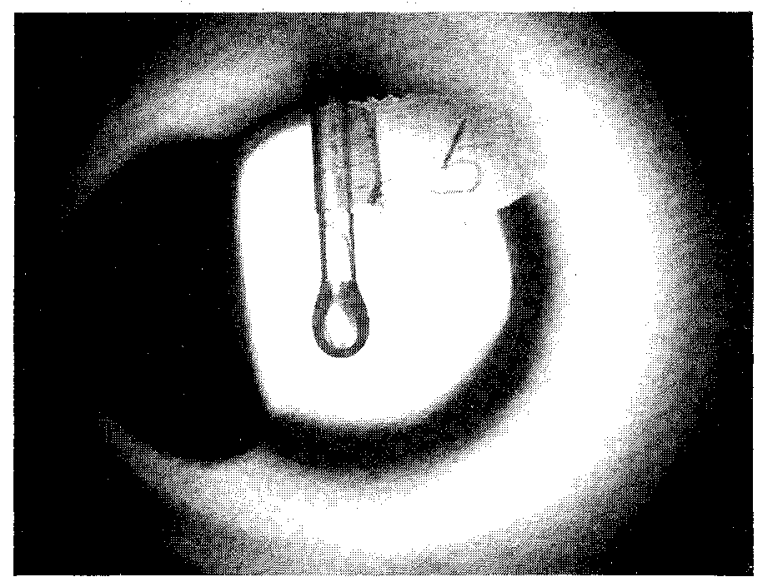

Fig. 9 Pendant drop pictures of various solutions at $22^{\circ} \mathrm{C}$; a) water, b) $50 \mathrm{mg} / \mathrm{ml}$.

Table 4 Surface tensions $(\mathrm{N} / \mathrm{m})$ of lysozyme solution at room temperature $\left(22^{\circ} \mathrm{C}\right)$

\begin{tabular}{cccccccc}
\hline & Water & Buffer & $10 \mathrm{mg} / \mathrm{ml}$ & $20 \mathrm{mg} / \mathrm{ml}$ & $30 \mathrm{mg} / \mathrm{ml}$ & $40 \mathrm{mg} / \mathrm{ml}$ & $50 \mathrm{mg} / \mathrm{ml}$ \\
\hline$\# 1$ & 0.0736 & 0.0582 & 0.0584 & 0.0582 & 0.0560 & 0.0553 & 0.0481 \\
$\# 2$ & 0.0737 & 0.0586 & 0.0584 & 0.0571 & 0.0587 & 0.0569 & 0.0520 \\
$\# 3$ & 0.0710 & 0.0601 & 0.0580 & 0.0580 & 0.0576 & 0.0526 & 0.0509 \\
$\# 4$ & 0.0716 & 0.0599 & 0.0575 & 0.0594 & 0.061 & 0.0528 & 0.0524 \\
$\# 5$ & 0.0707 & 0.0626 & 0.0587 & 0.0570 & 0.0581 & 0.0543 & 0.0505 \\
Average & $\mathbf{0 . 0 7 2 1}$ & 0.0596 & 0.0582 & 0.0579 & 0.0590 & 0.0544 & 0.0508 \\
\hline \hline
\end{tabular}

Table 5 Surface tensions $(\mathrm{N} / \mathrm{m})$ of lysozyme solution at $2^{\circ} \mathrm{C}$

\begin{tabular}{cccccccc}
\hline \hline & Water & Buffer & $10 \mathrm{mg} / \mathrm{ml}$ & $20 \mathrm{mg} / \mathrm{ml}$ & $30 \mathrm{mg} / \mathrm{ml}$ & $40 \mathrm{mg} / \mathrm{ml}$ & $50 \mathrm{mg} / \mathrm{ml}$ \\
\hline$\# 1$ & $\mathbf{0 . 0 4 6 7}$ & 0.0732 & 0.0711 & 0.0692 & 0.0689 & 0.0679 & 0.0630 \\
$\# 2$ & 0.0761 & 0.0732 & 0.0700 & 0.0674 & 0.0667 & 0.0666 & 0.0652 \\
$\# 3$ & 0.0744 & 0.0732 & 0.0688 & 0.0678 & 0.0662 & 0.0666 & 0.0659 \\
$\# 4$ & 0.0750 & 0.0725 & 0.0702 & 0.0671 & 0.0673 & 0.0680 & 0.0644 \\
$\# 5$ & $\mathbf{0 . 0 7 4 7}$ & 0.0723 & 0.0718 & 0.0668 & 0.0679 & 0.0679 & 0.0642 \\
Average & 0.0750 & 0.0727 & 0.0705 & 0.0672 & 0.0674 & 0.0674 & 0.0645 \\
\hline \hline
\end{tabular}




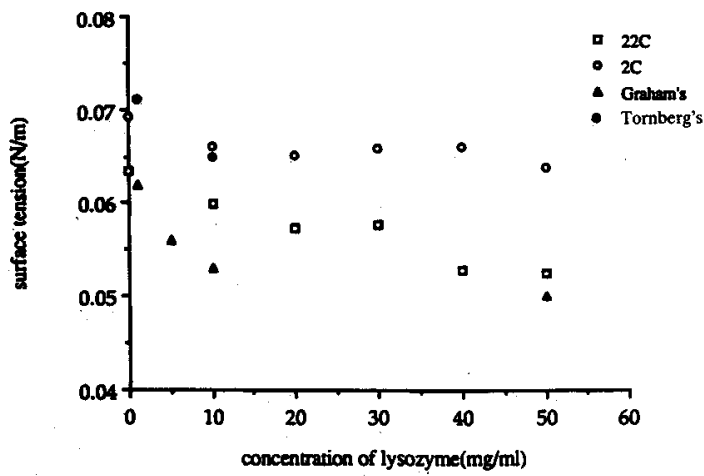

Fig. 10 Surfiace tension vs concentration.

reach equilibrium within $5 \mathrm{~min}$ of the formation of a new surface. 5,8 The measurements of five different drops were averaged, as shown in Tables 4 and 5 , to represent the surface tension for a given temperature and concentration. Again, the results from the measurements of water agree with the published data. The pictures of different pendant drops are shown in Fig. 9 and the averaged measurements are given in Fig. 10. The surface tension of all solutions of a given concentration are higher at $2^{\circ} \mathrm{C}$ than at $22^{\circ} \mathrm{C}$, a pattern that is similar to that of water. At constant temperature, the surface tension of the solutions studied resembles that of a weak electrolyte solution. The surface tension of a weak electrolyte solution decreases with an increase in solute concentration. The surface tension of a lysozyme solution decreases rapidly until a concentration of $20 \mathrm{mg} / \mathrm{ml}$ is reached. The surface tension remains constant up to $50 \mathrm{mg} / \mathrm{ml}$. This is true at $22^{\circ} \mathrm{C}$ and below. However, at low temperature, the surface tension is about $20 \%$ greater than at room temperature. It is also interesting to note that the surface tension coefficients, both with respect to temperature and concentration, are negative, a behavior found in almost all kinds of solutions except for strong electrolyte solutions. The Gray F/X image processing system has a precision of $1.25 \times 10^{-4} \mathrm{~m}$ in this measurement. When assuming there is negligible uncertainty in density difference between liquid and air, the uncertainty analysis yields an uncertainty of $3.5 \%$ for surface tension data.

Graham and Philips ${ }^{11}$ conducted a series of experiments on the interface of protein solutions. Besides studying the molecular structures and absorbed films, they also measured the surface pressure of lysozyme solutions using the Wilhelmy plate method. ${ }^{12}$ Since, by definition, the surface pressure is equal to the reduction of pure liquid surface tension by adding a second component, the data of Graham and Philips can be converted to surface tensions by subtracting surface pressure from the surface tension of water. The results after this conversion are plotted in Fig. 10. E. Thronberg and G. Lundh ${ }^{13}$ measured the surface tension for dilute lysozyme solutions, using the same buffer as Graham and Philips's, their results are also plotted in Fig. 10, for comparison. The deviations and scattering between the data in this section and the data provided by Graham and Philips, and Tornberg and G. Lundh are attributed to the variations in measuring methods, buffers, and experimental details.

\section{Conclusion}

The thermo-physical properties of lysozyme solutions were determined in this study. The thermal conductivity of lysozyme solutions, determined by means of a steady-state heating method, increases with an increase in temperature. An Ubbelohde viscometer is used to measure the viscosity of the lysozyme solutions which is constant in the range of concentrations from $0 \mathrm{mg} / \mathrm{ml}$ (buffer) to $20 \mathrm{mg} / \mathrm{ml}$. At higher concentrations, however, the viscosity increases rapidly with concentration. The specific heat is almost a constant over the concentration range investigated, as revealed by a DSC study. The pendant drop method is employed to measure the surface tension of lysozyme solutions. The surface tension coefficient is found to be negative, as is the case for water. The result is in good agreement with existing data.

\section{Acknowledgment} 903.

This work was funded in part by NASA under Grant NAG-

\section{References}

${ }^{1}$ Helliwell, J. R., "Synchrotron X-Ray Protein Crystallography: Instrumentation, Method and Applications," Reports on Progress in Physics, Vol. 47, 1984, pp. 1403-1497.

${ }^{2}$ DeLucas, L. J., and Bugg, C. E., "New Directions in Protein Crystal Growth," TIBTECH, Vol. 7, 1987, pp. 188-193.

${ }^{3}$ Flory, J. P., "The Configuration of Real Polymer Chains," Journal of Chemical Physics, Vol. 17, No. 3, 1949, pp. 303-310.

${ }^{4}$ Rabek, J. F., "Differential Thermal Analysis Methods," Experimental Methods in Polymer Chemistry, Wiley, New York, 1980, pp. $556-572$.

5Adamson, A. W., "Capillarity," Physical Chemistry of Surfaces, 3ed, Wiley-Interscience, New York, 1973, pp. 1-52.

${ }^{6}$ Young, R. J., "Transport Measurements," Introduction To Polymer, Chapman and Hall, New York, 1981, pp. 122-130.

${ }^{7}$ Gray, A. P., "A Simple Generalized Theory for Analysis of Dynamic Thermal Measurement," Analytical Calorimetry, edited by $\mathbf{R}$. S. Porter and J. F. Johnsons, Plenum Press, New York, 1968, p. 209.

${ }^{8}$ Andreas, J. M., Hauser, E. A. and Tucker, W. B., "'Boundary Tension by Pendant Drops," Journal of Physical Chemiistry, Vol. 42, No. 10, 1938, pp. 1001-1019.

${ }^{9}$ Giordano, R., Sallo, A., Salleo, S., and Wanderlingh, F., "Viscosity and Density of Lysozyme in Water," Physics Letters, Vol. 70A, No. 1, 1979, pp. 64-66.

${ }^{10}$ Pusey, M. L., Snyder, M. L., and Naumann, R., "Protein Crystal Growth - Growth Kinetics for Tetragonal Lysozyme Crystals," Journal of Biological Chemistry, Vol. 261, No. 14, 1986, pp. 6524-6529.

${ }^{11}$ Graham, G. L., and Philips, M. C., "Protein at Liquid Interface," Journal of Colloid and Interface Science, Vol. 70, No. 3, 1979, pp. 403-414.

${ }^{12}$ Gains, G. L., Insoluble Monolayer at Liquid-Gas Interface, Interscience, New York, 1966, p. 45.

${ }^{13}$ Tornberg, E., and Lundh, G., "A Study of the Surface Enlargement in the Drop Volume Method and Its Relation to Protein Adsorption at A/W, O/W interface," Colloid and Interface Science, Vol. 79, No. 1,1981 , pp. 76-84. 